\title{
THE LOCATION OF THE PHOTOPERIOD GENE, Ppd2 AND AN ADDITIONAL GENETIC FACTOR FOR EAR-EMERGENCE TIME ON CHROMOSOME 2B OF WHEAT
}

\author{
R. SCARTH AND C. N. LAW \\ Plant Breeding Institute, Trumpington, Cambridge CB2 $2 \mathrm{LO}$
}

Received 9.v.83

\begin{abstract}
SUMMARY
The major photoperiod gene $P p d 2$ was identified on chromosome $2 \mathrm{~B}$ of wheat using homozygous recombinant lines developed from a cross between Chinese Spring (CS) and the substitution line CS (Marquis 2B). Genetic analysis of these lines, using disease marker genes on the long arm of chromosome $2 \mathrm{~B}$, the yellow rust (Puccinia strifformis) gene $Y r 7$ and the stem rust $(P$. graminis) genes $S r 9 g$ and $\operatorname{Sr} 16$, showed these genes segregated independently from $P p d 2$. It was concluded that $P p d 2$ is located on the short arm of chromosome 2B. The classification of the disease resistance genes was used to identify a second gene(s) influencing the ear emergence time of the lines within each of the Ppd 2 and ppd 2 gene classes. The second gene(s) was associated with the disease genes on the long arm of chromosome $2 \mathrm{~B}$. The early allele of this gene(s) was found on Marquis chromosome $2 \mathrm{~B}$ and the late on Chinese Spring $2 \mathrm{~B}$, so that early alleles of the two gene(s) influencing ear emergence time in this study were dispersed between the parental chromosomes.

Following a winter sowing in the field, differences in ear emergence time were associated with the $P p d 2$ locus and the gene(s) on the long arm. Following a spring sowing, differences were confined to the gene(s) on the long-arm only. This confirms the photoperiodic sensitivity of $P p d 2$ and suggests that the second genetical effect was acting independently of the environment.
\end{abstract}

\section{INTRODUCTION}

Wheat is defined as a quantitative long-day plant (Vince-Prue, 1975). However, wheat cultivars vary in their photoperiod response from relatively insensitive through degrees of sensitivity to highly sensitive types which have greatly retarded development under short days. The variation available in this character has been critical in the development of varieties adapted to the wide range of day-length environments in which wheat is grown. A better understanding of the genetic control of the photoperiod response would assist wheat breeders in developing varieties adapted to specific environments (Pugsley, 1968).

Analyses of crosses between photoperiod sensitive and insensitive wheat varieties have defined two major genes controlling day-length response. The genes have been given the symbols $P p d 1$, dominant epistatic for insensitivity, and $P p d 2$, dominant for partial insensitivity (Keim, Welsh and McConnell, 1973).

Welsh, et al. (1973) assigned $P p d 1$ and $P p d 2$ to particular chromosomes on the basis of the ear emergence segregation of the $F_{2}$ progeny of crosses between the 21 monosomic lines of the variety Cheyenne (sensitive) with 
the variety Sonora 64 (insensitive). The dominant epistatic gene, $P p d 1$, was located on chromsome 2D since this F2 monosomic family lacked any late or very late segregants under short-day conditions. Chromosome $2 \mathrm{~B}$ was tentatively identified as the $P p d 2$ carrier, the $\mathrm{F}_{2}$ monosomic for this chromosome segregating to give the expected 3 early: 1 late with no very late segregants. The $\mathrm{F}_{2}$ monosomic families for chromosomes $4 \mathrm{~B}, 3 \mathrm{D}$ and $6 \mathrm{D}$ also gave acceptable segregations and could therefore not be dismissed as possible locations for Ppd2 (Pirasteh and Welsh, 1975). The location of these two major genes on chromosome $2 \mathrm{D}$ and possibly $2 \mathrm{~B}$ suggested the existence of homoeologous loci having similar functions on the group 2 chromosomes.

Law, Sutka and Worland (1978) studied the photoperiod and vernalisation response of a series of alien chromosome substitution lines, in which chromosome 2U from Aegilops umbellulata, 2M from Aegilops comosa and $2 \mathrm{R}^{\mathrm{m}}$ from Secale montanum were substituted for each of the Chinese Spring group 2 homoelogues. No differential response to vernalisation was found, but photoperiod effects were evident. While all three chromosomes had an effect on ear emergence time, the three alien substitutions for chromosome 2B produced the greatest delay under short days, suggesting that a major photoperiod gene conferring insensitivity was located on this chromosome in Chinese Spring.

This proposal was supported by a survey of aneuploid and intervarietal chromosome substitution lines for the group 2 chromosomes in Chinese Spring, under short and long photoperiods (Scarth, 1982). Large effects on ear emergence time under short photoperiods were associated with the deficiency of the short arm of chromosome 2B as in Chinese Spring ditelosomic 2BL and with the replacement of Chinese Spring chromosome 2B by homologous chromosomes from other varieties. The line in which chromosome 2B of the variety Marquis was substituted for 2B of Chinese Spring, CS(Marquis 2B), proved to be much more photoperiod sensitive than Chinese Spring. McIntosh (pers. comm. 1978) had noted the later maturity of this substitution line in the field, presumably a photoperiod response to the short day-length of the Australian growing season. While it is likely that the effect of chromosome 2B is due to the gene Ppd2, the location of $P p d 2$ on this chromosome was tentative and it was not determined how many factors were involved (Welsh et al., 1973). Before the response associated with this chromosome can be interpreted unequivocally as the action of a single major gene, further more penetrating studies are necessary. This study reports the genetical analysis of the chromosome $2 \mathrm{~B}$ effect on photoperiod response, using homozygous recombinant lines (Law, 1966, 1967).

\section{Materials and methods}

\section{(i) Genotypes}

The chromosome substitution line, CS(Marquis 2B), and the $\mathrm{F}_{1}$ hybrid between this line and Chinese Spring were provided by $\mathrm{Dr}$ R. A. McIntosh, Plant Breeding Institute, University of Sydney, Australia. CS monosomic 2B plants were obtained from stocks maintained at the Plant Breeding Institute, Cambridge. 


\section{(ii) Development of homozygous recombinant lines}

Following the procedures described by Law (1966), the $F_{1}$ was crossed to $\mathrm{CS}$ monosomic $2 \mathrm{~B}$ as the female parent and monosomic plants selected from the resulting progeny by cytological examination of root-tip cells. The hemizygous chromosomes in these plants will either be identical to the parental chromosomes and therefore non-recombinant or will have resulted from a cross-over event and therefore be recombinant. On selfing these plants, disomic homozygous recombinant lines were selected, again by cytological selection of root tips. Whenever possible, duplicate disomic selections were established from the selfing of each monosomic derivative. These duplicate lines will be identical for the chromosome under study but can differ for any gene distinguishing the background of the original substitution line from that of its recipient, therefore providing a measure of background variation.

For mitotic analysis, seedling root tips were pretreated in monobromonapthalene and stained by the Feulgen method. Meiotic studies were also carried out on the disomic lines, using Feulgen stained squashes of pollen mother cells taken from anthers fixed in acetic alcohol, to confirm that the lines had 42 chromosomes and that pairing was normal.

\section{(iii) Marker genes on chromosome $2 B$}

In choosing CS(Marquis 2B) as the substitution line for carrying out the analysis of the day-length response genes on chromosome 2B, consideration was given to the presence of gene markers. The 2B chromosome present in this line was known to carry the stem rust (Puccinia graminis) resistance genes $\mathrm{Sr} 9 \mathrm{~g}$ and $\mathrm{Sr} 16$ and the yellow rust $(P$. striiformis) resistance gene $Y r 7$ (McIntosh, pers. comm. 1978). Chinese Spring was known to be susceptible to the rust races used to test for the presence of these genes and therefore carries the corresponding recessive alleles $s r 9 g, s r 16$ and $y r 7$.

Sears and Loegering (1968) showed that both Sr9g and Sr16 were located on the long arm of chromosome 2B with little or no linkage between them. $\mathrm{Sr} 9 \mathrm{~g}$ was located 10.6 cross-over units from the centromere while Sr16 segregated independently. The yellow rust gene $Y r 7$ was reported to be closely linked to $\mathrm{Sr} 9 \mathrm{~g}$ (McIntosh, pers. comm. 1979).

An additional gene difference was reported between Chinese Spring and Marquis chromosome 2B, the D2 gene for hybrid dwarfing (Hermesen, 1967). This is one of a set of complementary dominant genes $D 1$ to $D 4$ which produces dwarf phenotypes in specific combinations e.g., D1D2D3. Chinese Spring has the recessive complement of all four dwarfing genes d1d2d3d4 (Hermesen, 1967; Worland and Law, 1980). McIntosh and Baker (1969) reported the location of $D 2$ as $42 \cdot 2$ cross-over units from $\mathrm{Sr}$.

These genes therefore provide a useful frame work for studying the location of other genes on chromosome 2B.

Dr R. A. McIntosh of the Plant Breeding Institute, University of Sydney, Australia, kindly undertook to carry out the screening of the recombinant lines for two races of stem rust which would distinguish the alleles at the $S r 9 g$ and $S r 16$ loci. The classification of the yellow rust gene $\mathrm{Yr} 7$ was carried out at the Plant Breeding Institute using the spores of the yellow rust race 37E132, provided by Dr R. Johnson of the Plant Breeding Institute, 
Cambridge. The method of testing followed that described in Johnson and Taylor (1974). Seedlings were classified as resistant ( $Y r 7)$ if the leaves showed no spore formation with a small amount of isolated leaf necrosis, or susceptible $(y r 7)$ if the leaves showed a large area of spore formation with wide areas of leaf necrosis.

A number of the recombinant lines, as well as Chinese Spring and CS(Marquis 2B), were crossed to the variety Timstein which carries the dwarfing genes $D 1$ and $D 3$. This test cross would detect lines carrying the $D 2$ gene as the combination $D 1-D 2-D 3$ - produces the dwarf phenotype.

\section{(iv) The experiments}

The photoperiod response of the recombinant lines was determined in two experiments, each carried out in a large controlled environment cabinet. The first experiment in 1979-80 involved 36 recombinant lines, nine of which were represented by duplicate lines, and the second in 1980-81 on 54 recombinant selections, 18 of which had duplicates. Twelve lines from the earlier study were included to provide a comparison between the two experiments.

Seed sufficient to provide six replicates in the first experiment and five in the second was pregerminated at $20^{\circ} \mathrm{C}$ and sown in $75 \mathrm{~mm}$ pots containing sterilized potting compost. Plants were arranged in a randomised block experimental design on self-watering sand benches. The light regime was 8 hours high intensity illumination. The temperature was a constant $18^{\circ} \pm$ $1^{\circ} \mathrm{C}$.

Twenty-seven recombinant lines including duplicates were also sown in the field during the winter of 1980 and the spring of 1981. Each sowing consisted of three randomised blocks, each composed of 54 lines sown as single row plots of seven plants. Each row of plants was $0.3 \mathrm{~m}$ apart and the seven plants within each row were spaced at $0.15 \mathrm{~m}$ intervals.

In all the experiments, the days from Day 1 of ear emergence were recorded.

\section{Results}

\section{(i) The identification of $P p d 2$}

Day 1 of ear emergence was 99 days after sowing in experiment 1 and 98 days in experiment 2 .

The analysis of variance of Experiments 1 and 2 is presented in table 1. The overall "Line" sum of squares can be divided into the variation due to duplicates within the lines and the residual or true "Between Lines" item.

The duplicate variation was not significant in either experiment. Therefore, the observed variation is due to the genetic differences between the 2B chromosomes and not to segregation between the background chromosomes.

The "Between Line" variation is represented in histogram form in fig. 1 for the distribution of the mean ear emergence times of the lines at two day intervals. In those lines for which duplicates were included, the line mean used in compiling the distributions was based on the mean of the duplicates. 
TABLE 1

Analysis of ear emergence time amongst recombinant lines derived from the cross of Chinese Spring with CS(Marquis 2B) in two experiments

\begin{tabular}{lrc}
\hline \multicolumn{1}{c}{ Source of Variation } & $\mathrm{df}$ & $\mathrm{MS}$ \\
\hline Experiment 1 & & \\
Overall Lines & 44 & $505 \cdot 25^{*}$ \\
$\quad$ Duplicates & 9 & $15 \cdot 35$ \\
Between Lines & 35 & $631 \cdot 23^{*}$ \\
$\quad$ Early v Late Ear emergence class & 1 & $19859 \cdot 71^{*}$ \\
$\quad$ Residual between line & 34 & $65 \cdot 69^{*}$ \\
$\quad$ Error (within line) & 200 & 29.87 \\
Experiment 2 & 71 & $249 \cdot 94^{*}$ \\
Overall lines & 18 & $13 \cdot 25$ \\
$\quad$ Duplicates & 53 & $330 \cdot 32^{*}$ \\
Between lines & 1 & $15912 \cdot 73^{*}$ \\
$\quad$ Early v Late Ear emergence class & 52 & $30 \cdot 66^{*}$ \\
$\quad$ Residual between line & 248 & $13 \cdot 33$ \\
Error (within line) & & \\
\hline
\end{tabular}

* Significant at $\mathrm{P}<0 \cdot 01$.

In Experiment 1, the distribution was basically bimodal. Early and late designations were assigned to the lines with ear emergence times less or greater than 18 days from the start of ear emergence. The "Between Line" variation (table 1) accounted for by these two major gene classes was found to be highly significant, confirming that the two classes represent a real division in the ear emergence times between the lines. The 36 lines can therefore be divided into 17 early and 19 late lines, an acceptable fit to a 1:1 ratio. This indicates the segregation of a single factor between the lines.

The distribution obtained in Experiment 2 was discontinuous and two separate modes were produced, 22 lines being early and 33 being late. This classification also accounts for a significant part of the "Between Line" variation.

Twelve of the lines were grown in both experiments. The means of these lines in the two experiments showed a close correlation $(r=0.99 \pm 0.075$, $P<0.001)$. The line classification into early and late therefore agrees between experiments, so that it is possible to pool the data to give an overall segregation of 33 early to 45 late lines. This again agrees with a 1:1 ratio $\left(\chi_{\{1\}}^{2}=1 \cdot 85, \mathrm{P} 0 \cdot 2-0 \cdot 1\right)$, and therefore supports a single major gene, $P p d 2$, as being responsible for the differences in ear emergence times between the lines. Almost certainly this single gene is the gene $P p d 2$ proposed by Welsh et al., (1973). The location of a major photoperiod gene on chromosome $2 \mathrm{~B}$ is therefore confirmed.

In both experiments, removal of the early versus late (i.e., $P p d 2$ versus ppd2) comparisons from the "Between Line" variation left a residual which was still significant. Therefore, although the variation due to $P p d 2$ versus ppd 2 accounts for the major part of the variation between the lines, there is still variation within each of the two modes. Because of the absence of duplicate variation, this variation must relate to chromosome $2 \mathrm{~B}$. One possible explanation is misclassification of the lines into early and late, particularly in the first experiment. Alternatively, a second gene on chromosome $2 \mathrm{~B}$ may be influencing ear emergence time within the $P p d$ gene classes. 


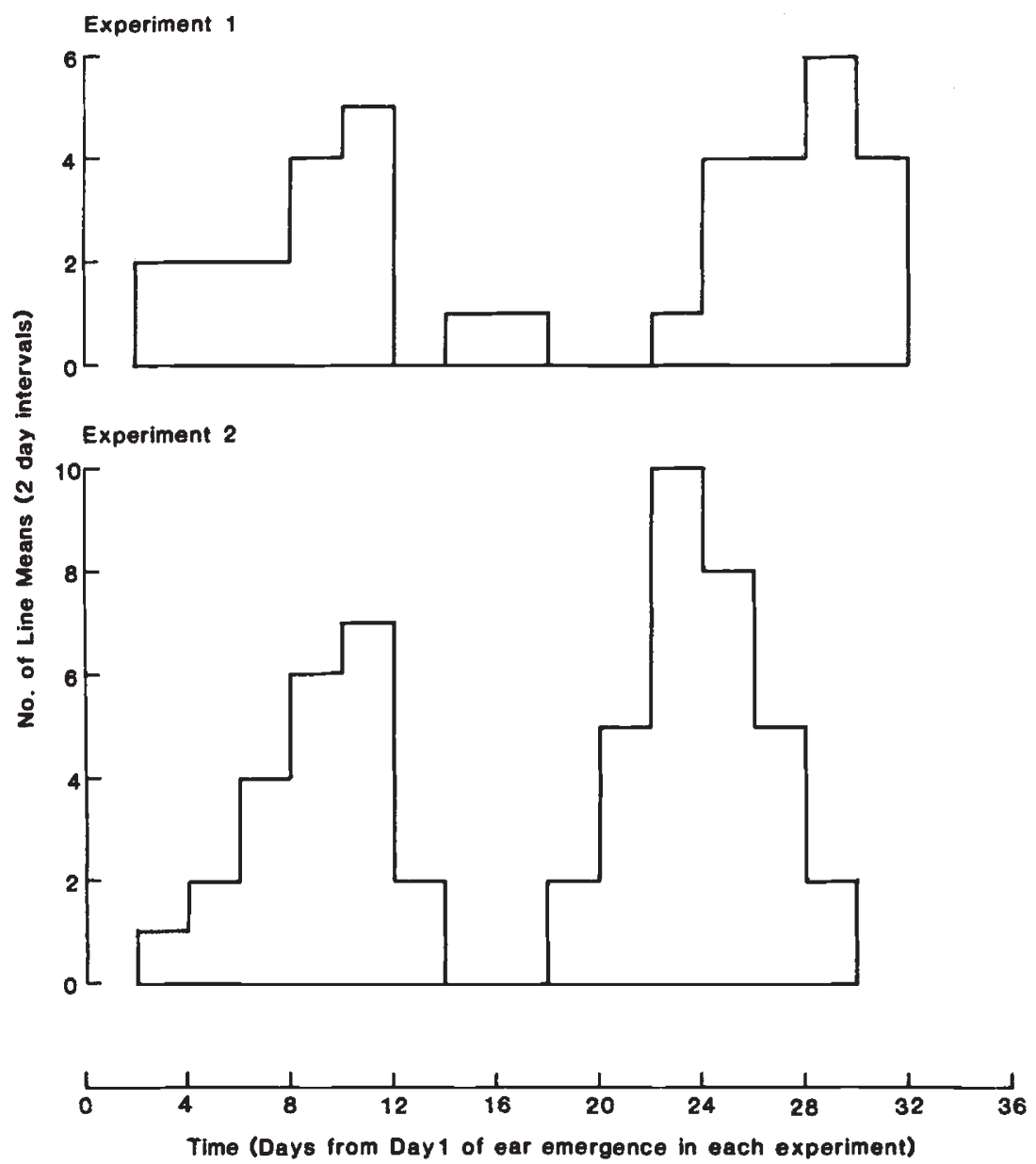

FIG. 1. Mean ear emergence times of recombinant lines in Experiments 1 and 2.

(ii) Location of genes on chromosome $2 B$

None of the hybrids from the test cross with Timstein were dwarfed, indicating the total lack of $D 2$ in the lines being tested. This unexpected result supports the claim of Sheen and Snyder (1964). These workers, from the laboratory which originally developed the Marquis substitution lines, suspected that the donor parent was a hybrid between Thatcher and Marquis, rather than Marquis itself. Thus, it would appear that CS(Marquis 2B) is possibly CS(Thatcher 2B), since Thatcher is known to carry the same resistance gene as Marquis (McIntosh, 1977) but lacks D2 (Hermesen, 1967).

The results of the yellow rust tests were combined with those from the stem rust tests so that each line was classified for the segregation of these gene loci (with the exception of four lines for which only yellow rust gene classification was obtained). In every case, duplicate lines agreed in their disease gene classification. This indicates that these genes are located on 
chromosome $2 \mathrm{~B}$, thereby confirming earlier reports. Also, the segregation of the yellow rust gene $\mathrm{Yr} 7$ agreed exactly with the segregation of the stem rust gene $S r 9 g$, so that the two genes are closely linked and, as far as this experiment is concerned, can be regarded as a single gene. Again, this tight linkage agrees with earlier reports (McIntosh, pers. comm. 1979).

Eight classes are possible where three genes are segregating and the numbers in each of these classes are indicated in table 2. These eight classes produce seven degrees of freedom which can be assigned to test departures from the expected $1: 1$ ratio for each gene ( 3 d.f.) as well as the test for independence of linkage between them ( 4 d.f.). These tests can be carried out by means of a heterogeneity $\chi^{2}$ and the comparisons giving rise to these are shown (table 2). None of these is significant, indicating that all the genes segregate independently from each other. The estimates of recombination between them are as follows:

Recombination

Ppd2-Yr7Sr9g
Yr7Sr9g-Sr16
Ppd2-Sr16

$\operatorname{Ppd2-Yr7Sr9g}$

Ppd2-Sr16
$33 / 74=0.45 \pm 0.057$
$41 / 74=0.54 \pm 0.060$
$36 / 74=0.49 \pm 0.057$

The estimate for the $\mathrm{Sr} 9 \mathrm{~g}-\mathrm{Sr} 16$ genes agrees with previously determined estimates of recombination between these two genes. As these genes segregate independently, the evidence that they are all in fact on chromosome $2 \mathrm{~B}$ stems entirely from the lack of segregation between the duplicates.

The independent segregation of $P p d 2$ from $Y r 7 S r 9 g$ suggests that $P p d 2$ is located on the short arm of chromosome 2B. Previous information about the genetic map of $2 \mathrm{~B}$ places $\mathrm{Yr} 7 \mathrm{Sr} 9 \mathrm{~g}$ about 20 centimorgans from the centromere and $\operatorname{Sr} 16$ distal to this and at least 70 centimorgans out on the long arm (Sears and Loegering, 1968). For $P p d 2$ to be distal to and independent of $\operatorname{Sr} 16$ would call for a map distance in excess of 120 centimorgans on the long arm. Such a map distance is very unlikely in wheat where the mean chiasma frequencies per arm are invariably less than two, indicating a distance of less than 100 centimorgans (Riley and Law, 1965).

The location of $P p d 2$ on the short arm of chromosome $2 \mathrm{~B}$ is also supported by the sensitivity of the CS ditelosomic line $2 \mathrm{~B}^{\mathrm{L}}$ in which this arm is absent, (Scarth, 1982).

The classification of the recombinant lines in terms of their segregation for yellow rust and stem rust genes allows a further analysis of the residual genetic variation not accounted for by the segregation of $P p d 2$ in the ear emergence study. The "Between Line" variation can now be partitioned to take into account the effects of the eight major classes of genotype. The consequence of removing these seven degrees of freedom is given in table 3. In both experiments, the major gene groups are highly significant. More important, however, is the fact that the residual items are no longer significant, in contrast to the previous analysis using the $P p d 2$ gene classification alone.

The genetic variation in ear emergence time not accounted for by $P p d 2$ must therefore be associated with the disease resistance genes located on the long arm of chromosome 2B. This is supported by the examination of the mean ear emergence time of the lines carrying each of the four combinations of disease resistance genes within the $P p d 2$ and $p p d 2$ classes (table 


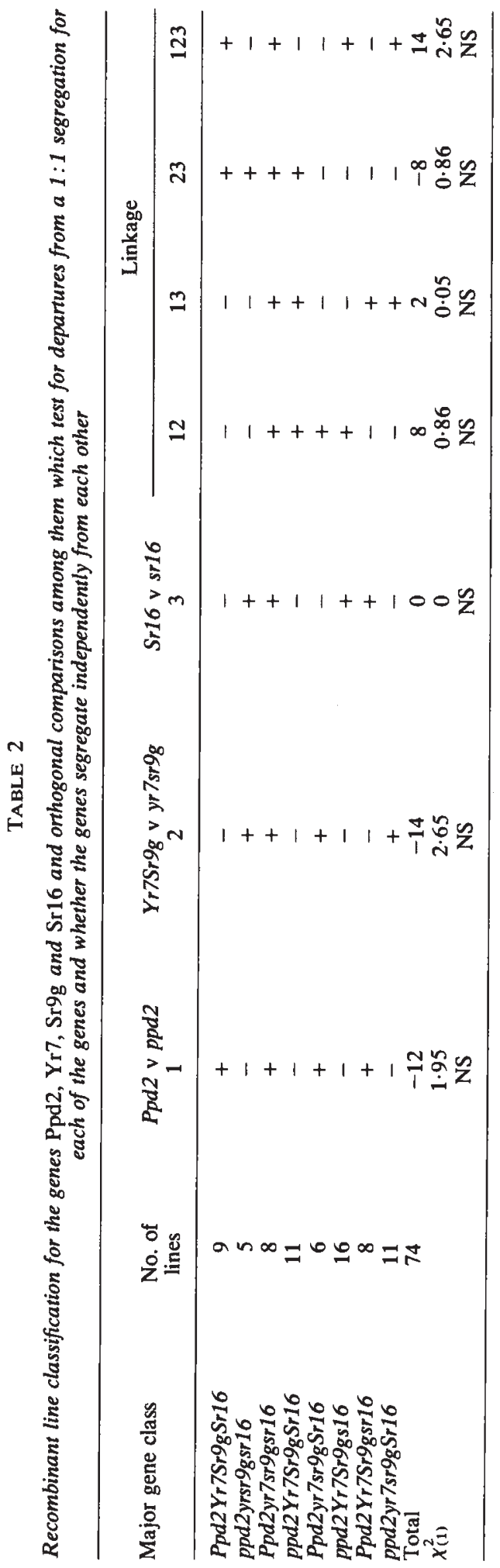


TABLE 3

Analysis of ear emergence time amongst recombinant lines derived from the cross of Chinese Spring with CS(Marquis 2B) in two experiments (8-hour photoperiod at $18^{\circ} \mathrm{C}$ ), using the partitioning of the lines into classes according to the major genes, $\mathrm{Ppd} 2, \mathrm{YrSr} 9 \mathrm{~g}$ and $\operatorname{Sr} 16$

\begin{tabular}{lrc}
\hline Source of variation & df & MS \\
\hline Experiment 1 & 35 & $631 \cdot 23^{*}$ \\
Between lines & 7 & $3003 \cdot 78^{*}$ \\
$\quad$ Major gene classes & 28 & 38.09 \\
Residual between lines & 200 & $29 \cdot 87$ \\
$\quad$ Error (within lines) & 49 & $340 \cdot 376^{*}$ \\
Experiment 2 & 7 & $2259 \cdot 22^{*}$ \\
Between lines & 42 & $20 \cdot 57$ \\
Major gene classes & 229 & 14.75 \\
Residual between lines & & \\
Error (within lines) & & \\
\hline
\end{tabular}

* Significant at $\mathrm{P}<0.01$.

4). In nearly all cases, the means of $\operatorname{Yr} 7 \operatorname{Sr} 9 g S r 16$ and $y r 7 s r 9 g s r 16$, the two non-recombinant classes, are low and high respectively whereas the means of the two recombinant classes, $Y r 7 S r 9 g s r 16$ and $y r 7 s r 9 g S r 16$, are both intermediate. These differences are explicable if a gene(s) affecting ear emergence is located between $\mathrm{Yr} 7 \mathrm{Sr} 9 \mathrm{~g}$ and $\operatorname{Sr} 16$ with the late allele(s) on Chinese Spring 2B and the early on Marquis 2B. Non-recombinants between the disease resistance genes would thus tend to have parental values, whereas the mean ear emergence time of the recombinants would tend to be intermediate.

TABLE 4

Mean ear emergence time and its analysis for eight gene classes within the recombinant lines in Experiment 1 and 2. (Repeated lines were removed from Experiment 2)

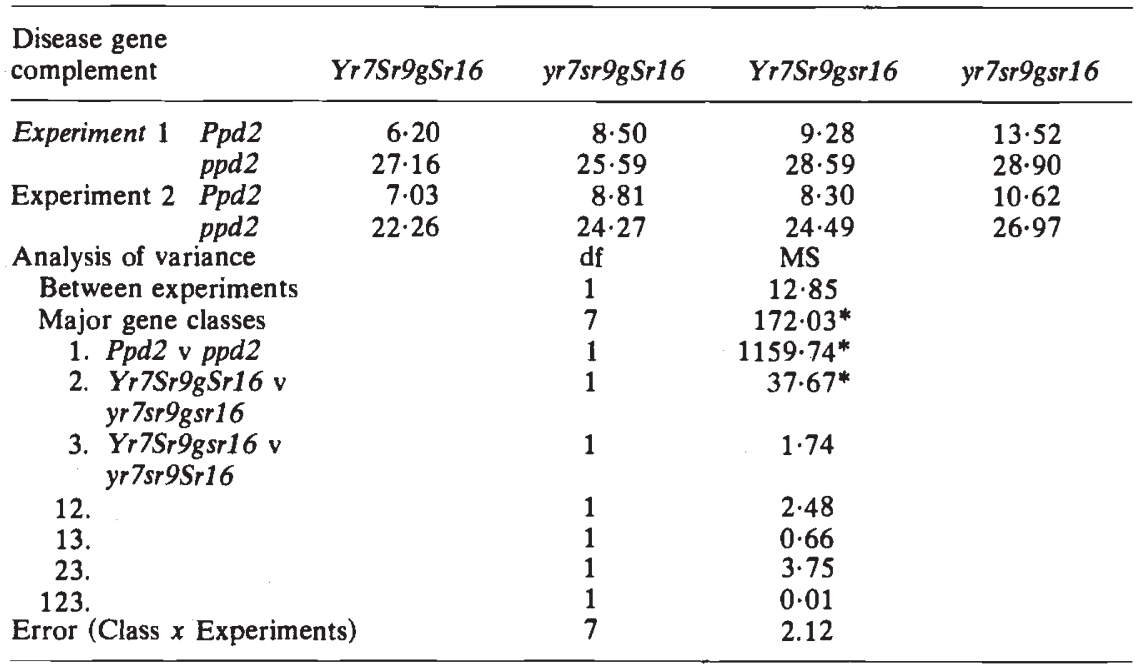

* Significant at $\mathrm{P}<0.01$. 
That this pattern is significant and is constant over experiments is demonstrated by analysing the means for each of the eight classes, using the differences between the experiments as a measure of error (table 4). The 15 degrees of freedom available in the combined study can be divided into the variation due to the eight major gene classes ( 7 d.f.), differences between the experiments, ( 1 d.f.), and a class $x$ experiment interaction or error ( 7 d.f.) The variation between the major gene classes can then be partitioned into differences between $P p d 2$ and $p p d 2$, between the means of the two non-recombinant gene combinations, between the means of the two recombinant gene combinations, and the interaction between these comparisons to account for the remaining 4 d.f.

This analysis (Table 4) confirms the observation that the means of the lines carrying the two parental or non-recombinant disease gene combinations have different ear emergence times, while the means of the lines carrying the two recombinant disease gene combinations are indistinguishable from each other.

This separation can be seen in fig. 2 where the two experiments have been combined by equating Day 1 of ear emergence in each experiment. The distribution of the four disease resistance classes within each of the Ppd 2 and $p p d 2$ modes follows the pattern indicated in the analysis of variance.

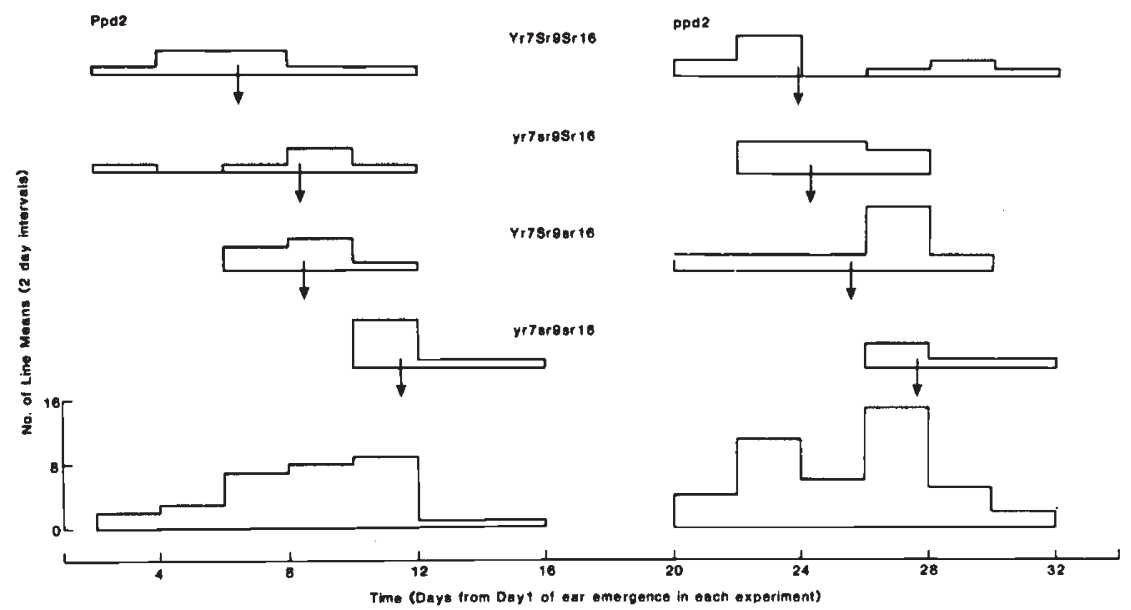

FIG. 2. Mean ear emergence times of recombinant lines in Experiment 1 and 2 combined and grouped into four disease resistance classes within each of the early $(P p d 2)$ and late (ppd2) emergence classes.

Therefore a gene(s) modifying ear emergence time within the $P p d 2$ gene classes is located between $\mathrm{Yr} 7 \mathrm{Sr} 9 \mathrm{~g}$ and $\mathrm{Sr} 16$ on the long arm of chromosome 2B. As already mentioned, this gene(s) on Marquis $2 \mathrm{~B}$ is for earliness and its allele on Chinese Spring $2 \mathrm{~B}$ is for lateness. This is the opposite of $P p d 2$ so that the earliness alleles of these ear emergence genes are dispersed between the two chromosomes. The relationship between $P p d 2$ and the gene(s) on the long arm is not certain. The analysis of the major gene classes showed no significant interaction between the two sets of genes, 
indicating that the second gene(s) influences ear emergence time independently. Since the experiments were carried out under short days, it is not possible to be certain about the influence on day-length sensitivity of the gene(s) on the long arm.

\section{(iii) Behaviour of the recombinant lines in the field}

The analysis of the variation in ear-emergence time amongst the recombinant lines is given separately for the winter and spring sowings in table 5. Significant differences were detected between lines in both sowings. In the spring sown experiment, significant duplicate variation was observed for the first time. Despite this unexpected and unaccountable feature, variation between the lines was much larger in the winter, the major part of this increased variation being due to the effect of $P p d 2$. This was not evident in the spring sown experiment. Presumably this reflects the influence of the short days on the early development of plants sown in the winter.

Apart from the influence of $P p d 2$ the analysis of the winter sown experiment indicated a significant residual variation which could not be ascribed to either $\mathrm{Yr} 7 \mathrm{Sr} 9 \mathrm{~g}$ or $\mathrm{Sr} 16$. In the analysis of the spring sown experiment, this residual variation was negligible but some of the "Between

TABLE 5

Separate analyses of ear-emergence time amongst recombinant lines in winter and spring field sowings

\begin{tabular}{lrrl}
\hline Source of variation & df & MS & VR \\
\hline Winter sowing & & & \\
$\quad$ Lines & 26 & $8 \cdot 82$ & $7 \cdot 54^{* * * *}$ \\
Major gene classes & 7 & $20 \cdot 88$ & $6 \cdot 24^{* * *}$ \\
Ppd2 & 1 & $108 \cdot 02$ & $24 \cdot 66^{* * * *}$ \\
Residual & 6 & $6 \cdot 35$ & $1 \cdot 45$ \\
YrSr9g & 1 & $1 \cdot 91$ & $0 \cdot 44$ \\
Residual & 6 & $24 \cdot 94$ & $5 \cdot 48^{* * *}$ \\
Sr16 & 1 & $0 \cdot 07$ & $0 \cdot 01$ \\
Residual & 6 & $24 \cdot 34$ & $5 \cdot 55^{* *}$ \\
Residual line & 19 & $4 \cdot 38$ & $4 \cdot 75^{* * *}$ \\
Duplicates & 27 & $1 \cdot 97$ & $1 \cdot 68$ \\
Error & 102 & $1 \cdot 17$ & \\
Spring Sowing & & & \\
Lines & 26 & $2 \cdot 92$ & $3 \cdot 83^{* * *}$ \\
Major gene clases & 7 & $5 \cdot 35$ & $2 \cdot 64^{*} \dagger$ \\
Ppd2 & 1 & $3 \cdot 19$ & $1 \cdot 57$ \\
Residual & 6 & $5 \cdot 71$ & $2 \cdot 82^{*}$ \\
YrSr9g & 1 & $8 \cdot 25$ & $4 \cdot 07$ \\
Residual & 6 & $4 \cdot 86$ & $2 \cdot 40$ \\
Sr16 & 1 & $5 \cdot 51$ & $2 \cdot 72$ \\
Residual & $5 \cdot 32$ & $2 \cdot 63$ \\
Residual line & 19 & $2 \cdot 03$ & $0 \cdot 88$ \\
Duplicates & 27 & $2 \cdot 31$ & $3 \cdot 03^{* * *}$ \\
Error & 104 & $0 \cdot 76$ & \\
\hline
\end{tabular}

* $\mathrm{P}=0.05-0.01, \quad * * \mathrm{P}=0.01-0.001, \quad * * * \mathrm{P}<0.001$.

† VR calculated against MS Residual line as error. 
Line" variation was associated with the segregation of the major gene classes since this comparison was significant.

It is possible that this variation may arise from the second gene(s) located on the long-arm of 2B between $Y r 7 S r 9 g$ and $S r 16$. A test of this is to compare the variation in ear-emergence time within each of the $P p d 2$ classes observed in the controlled environment experiments with that observed in the field. For both the winter and spring sowings, within the $P p d 2$ classes, significant correlations occur $(r=0.65 \pm 0.26, P$ 0.05-0.01 and $r=0.81 \pm$ $0.21, P 0.01-0.001$ respectively). In the case of the ppd2 classes, the correlations are positive but not significant ( $r=0.10 \pm 0.26$ in both cases). This therefore suggests that the variation located in the previous experiments on the long-arm of 2B is also expressed in the field. Moreover, unlike Ppd2, this effect can be observed in both sowing experiments, suggesting that the gene or genes responsible are not sensitive to day-length, nor indeed to vernalisation since a certain consequence of the winter sowing would have been to remove this effect.

\section{Conclusions}

The single major gene in this study is undoubtedly the $P p d 2$ gene of Welsh et al., (1973). Chinese Spring carries a potent insensitive allele of Ppd2 on chromosome 2B. This confirms the proposal of Law et al., (1978) that a major photoperiod gene is responsible for the delay in ear emergence which occurs when Chinese Spring $2 \mathrm{~B}$ is removed in alien and intervarietal chromosome substitution lines under short days. Chromosome $2 \mathrm{~B}$ of the Marquis-Thatcher hybrid used in the production of CS(Marquis 2B) was shown in this study to carry the sensitive allele of $P p d 2$.

The $P p d 2$ gene is located on the short arm of chromosome $2 \mathrm{~B}$ and segregates independently from the disease gene markers $\mathrm{Yr} 7, \mathrm{Sr} 9 \mathrm{~g}$ and Sr16 on the long arm. The location is supported by the sensitive response of the Chinese Spring aneuploid line in which the short arm is absent, CS ditelo 2BL (Scarth, 1982).

The influence of $P p d 2$ was seen in the ear emergence times of the lines in the winter sowing. This suggests that it is variation at this locus and related loci on 2A and 2D (Welsh et al., 1973; Law et al., 1978), which is responsible for control of major parts of the maturity times of winter sown cereals in the UK and elsewhere. It also suggests that the time of action of the gene is during early development which would take place in the field under the short day-lengths of winter.

A study of the development of some of the recombinent lines used in this study has established that $P p d 2$ influences the growth of the ear following the initiation and the completion of the formation of spikelet primordia (Scarth, Kirby and Law, 1983). The sensitive allele under short days retards ear growth and consequently floral development and stem internode elongation.

A second gene(s) modifying ear emergence time within the $P p d 2$ gene classes was identified on the long arm of chromosome $2 \mathrm{~B}$. In the development study, the influence of this second gene(s) also appeared to influence ear growth. The late allele(s), associated with the disease resistance genes on Chinese Spring 2B, slowed ear growth and therefore reproductive development. The results of the field sowings suggested this gene(s) was 
acting independently of the environment and therefore is not a vernalisation or a day-length response gene. While the alleles affecting this character in Chinese Spring and Marquis $2 \mathrm{~B}$ were less potent than Ppd2, it is possible that alleles from other varietal sources may have a major effect on ear emergence through their influence on ear growth and reproductive development.

Acknowledgements. The authors would like to acknowledge the help provided by Dr R. A. McIntosh in screening the material for stem rust as well as the help and advice of $\mathrm{Mr} \mathrm{A}$. J. Worland in carrying out the experiments. R. S. would also like to thank the Canadian National Research Council and the Perry Foundation for financial support.

\section{REFERENCES}

HERMESEN, J. G. TN. 1967. Hybrid dwarfness in wheat. Euphytica 16, 134-162.

JOHNSON, R. AND TAYLOR, A. J. 1974. Yellow rust of wheat. Plant Breeding Institute, Cambridge, Annual Report, 139-142.

KEIM, D. L.. WELSH, J. R. AND MCCONNELL, R. L. 1973. Inheritance of photoperiodic heading response in winter and spring cultivars of bread wheat. Can. J. Plant Science 53, 247-250.

LAW, C. N. 1966. The location of genetic factors affecting a quantitative character in wheat. Genetics 53, 487-498.

LAW, C. N. 1967. The location of genetic factors controlling a number of quantitative characters in wheat. Genetics 56, 445-461.

LAW, C. N., SUTKA, J. AND WORLAND. A. J. 1978. A genetic study of day-length response in wheat. Heredity $41,185-191$.

MCintosh, R. A. 1977. Catalogue of gene symbols for wheat, 1977 supplement. Wheat Information Service, 45 and 46, 54-55.

MCINTOSH, R. A. AND BAKER, E. P. 1969. Telecentric mapping of a second gene for grassclumb dwarfiing. Wheat Information Service, 29, 6-7.

PIRASTEH, B. AND WELSH, J. R. 1975. Monosomic analysis of photoperiod response in wheat. Crop Science 15, 503-505.

PUGSLEY, A. T. 1968. Genetic studies of phasic development and their application to wheat breeding. Proc. 3rd Int. Wheat Genet. Symp., Canberra, 188-293.

RILEY, R. AND LAW, C. N. 1965. Genetic variation in chromosome pairing. Advances in genetics Vol. 13, 57-107.

SCARTH, R. 1982. The genetic control of daylength response in wheat and its effect on development. Ph. D. Thesis, Camb.

SCARTH, R., KIRBY, E. J. M. AND LAW, C. N. 1983. The effect of the photoperiod genes Ppd1 and $P p d 2$ on development in wheat. (in preparation).

SEARS, E. R. AND LOEGERING, W. Q. 1968. Mapping of stem rust genes $\operatorname{Sr} 9 \operatorname{Sr} 16$ of wheat. Crop Science 8, 731-3.

SHEEN, S. J. AND SNYDER, L. A. 1964. Studies on the inheritance of resistance to six stem rust cultures using chromosome substitution lines of a Marquis wheat selection. Can. J. Genet. Cytol. 6, 74-82.

VINCE-PRUE, D. 1975. Photoperiodism in plants, McGraw-Hill, London.

WELSH, J. R., KEIM, D. L., PIRASTEH, B. AND RICHARDS, R. D. 1973. Genetic control of photoperiod response in wheat. Proc. 4th Int. Wheat Genet. Symp. Missouri, 879-884.

WORLAND, A. J. AND LAW, C. N. 1980. The genetics of hybrid dwarfing in wheat. $Z$. Pflanzenzüchtg. 85, 28-39. 